\title{
Temperature Prediction Using Fuzzy Time Series
}

\author{
Shyi-Ming Chen, Senior Member, IEEE, and Jeng-Ren Hwang
}

\begin{abstract}
A drawback of traditional forecasting methods is that they can not deal with forecasting problems in which the historical data are represented by linguistic values. Using fuzzy time series to deal with forecasting problems can overcome this drawback. In this paper, we propose a new fuzzy time series model called the two-factors time-variant fuzzy time series model to deal with forecasting problems. Based on the proposed model, we develop two algorithms for temperature prediction. Both algorithms have the advantage of obtaining good forecasting results.
\end{abstract}

Index Terms-Main-factor fuzzy time series, second-factor fuzzy time series, temperature prediction, time-invariant fuzzy time series, time-variant fuzzy time series.

\section{INTRODUCTION}

I $\mathrm{T}$ is obvious that forecasting activities play an important role in our daily life. Every day the weather forecast tells us what the weather will be like tomorrow. We can prevent huge damage by forecasting the coming of storms or typhoons. We usually forecast many things concerned with our daily life, such as economy, stock market, population growth, weather, etc. To make a forecast with $100 \%$ accuracy may be impossible, but we can do our best to reduce the forecasting errors or increase the speed of the forecasting process. To solve the forecasting problems, many researchers have proposed many different methods or models. A drawback of traditional forecasting methods is that they can not deal with forecasting problems in which the historical data are linguistic values. In order to overcome the drawback of the traditional forecasting methods, in [17], Song and Chissom proposed the concepts of fuzzy time series to deal with the forecasting problem in which the historical data are linguistic values. In [18] and [19], they proposed two fuzzy time series models to deal with the forecasting problems for forecasting enrollments of the University of Alabama.

In [18], Song et al. use the following method to forecast enrollments of the University of Alabama:

$$
F(t)=F(t-1) \circ R
$$

where

$F(t-1) \quad$ fuzzified enrollment of year $t-1$;

$F(t) \quad$ forecasted enrollment of year $t$ represented by fuzzy sets;

Manuscript received May 13, 1998; revised January 5, 2000. This work was supported in part by the National Science Council, R.O.C., under Grant NSC 85-2213-E-009-123. This paper was recommended by Associate Editor A. Kandel.

S.-M. Chen is with the Department of Electronic Engineering, National Taiwan University of Science and Technology, Taipei, Taiwan, R.O.C.

J.-R. Hwang is with the Department of Computer and Information Science, National Chiao-Tung University, Hsinchu 300, Taiwan, R.O.C.

Publisher Item Identifier S 1083-4419(00)02965-4.
$R \quad$ union of fuzzy relations;

"o" Max-Min composition operator.

It takes a lot of time to compute the union of fuzzy relations $R$, but it is computed only once. In [19], Song et al.proposed the time-variant fuzzy time series model. The model also uses (1), but the calculation of the union of fuzzy relations $R$ is different from the method in [18]. The method presented in [19] takes less time to compute the union of fuzzy relations $R$, but it must recalculate $R$ when we want to forecast the enrollments of different years. The time complexities of the methods in [18] and [19] are all $O\left(k n^{2}\right)$, where $k$ is the number of fuzzy logical relationships, and $n$ is the number of elements in the universe of discourse. Although some researchers have proposed new fuzzy time series models to improve Song's model, such as [4], [5], [7], and [21], all of these models can only deal with one-factor forecasting problems. In [4], we presented a time-invariant fuzzy time series method to forecast university enrollments. In [5], Day proposed a time-variant fuzzy time series model which used expert opinions and genetic algorithms. In [7], we presented a one-factor time-variant fuzzy time series model and proposed an algorithm for handling forecasting problems. In [21], Sullivan et al. proposed the Markov model which used linguistic labels with probability distributions.

In this paper, we propose a new fuzzy time series model which is called the "two-factors time-variant fuzzy time series model" to deal with forecasting problems. Based on the proposed model, we develop two algorithms for temperature prediction. The proposed algorithms have the advantage that they can obtain good forecasting results.

The rest of this paper is organized as follows. In Section II, we briefly review some basic concepts of fuzzy set theory [8]-[11], [28] and fuzzy time series [17]-[19]. In Section III, we propose the two-factors time-variant fuzzy time series model and propose two efficient algorithms for temperature prediction. The conclusions are discussed in Section IV.

\section{Fuzzy Set Theory And Fuzzy Time Series}

In the following, we briefly review some basic concepts of fuzzy set theory from [8]-[11], and [28]. A fuzzy set is a class with fuzzy boundaries. A fuzzy set can be characterized by a membership function defined as follows.

Definition 2.1: Let $U$ be the universe of discourse. A fuzzy subset $A$ on the universe of discourse $U$ can be defined as follows:

$$
A=\left\{\left(u_{i}, \mu_{A}\left(u_{i}\right)\right) \mid u_{i} \in U\right\}
$$

where $\mu_{A}$ is the membership function of $A, \mu_{A}: U \rightarrow[0,1]$, and $\mu_{A}\left(u_{i}\right)$ is the degree of membership of the element $u_{i}$ in the fuzzy set $A$. 
Definition 2.2: Let $U$ be the universe of discourse, $U=$ $\left\{u_{1}, u_{2}, \ldots, u_{n}\right\}$, and $U$ be a finite set. A fuzzy set $A$ can be expressed as follows:

$$
\begin{aligned}
A & =\sum_{i=1}^{n} \mu_{A}\left(u_{i}\right) / u_{i} \\
& =\mu_{A}\left(u_{1}\right) / u_{1}+\mu_{A}\left(u_{2}\right) / u_{2}+\cdots+\mu_{A}\left(u_{n}\right) / u_{n}
\end{aligned}
$$

where the symbol " + " means the operation of union instead of the operation of summation, and the symbol "/" means the seperator rather than the commonly used algebraic symbol of division.

Definition 2.3: Let $U$ be the universe of discourse, where $U$ is an infinite set. A fuzzy set $A$ of $U$ can be expressed as follows:

$$
A=\int_{U} \mu_{A}\left(u_{i}\right) / u_{i}, \quad \forall u_{i} \in U .
$$

Definition 2.4: Let $A$ be a fuzzy set of the universe of discourse $U$. The $\alpha$-significance level [27] $A_{\alpha}$ of the fuzzy set $A$ is defined as follows:

$$
\mu_{A_{\alpha}}(u)= \begin{cases}\mu_{A}(u), & \text { if } \mu_{A}(u) \geq \alpha \\ 0, & \text { otherwise }\end{cases}
$$

where $\alpha \in[0,1]$.

The concept of fuzzy time series was proposed by Song et al. [17]. In a traditional time series, the values of observations of a special dynamic process are represented by crisp numerical values. However, in a fuzzy time series, the values of observations of a special dynamic process are represented by linguistic values. In [18] and [19], Song et al. used the fuzzy time series to forecast the enrollments of the University of Alabama, and they got good forecasting results. In the following, we briefly review the concept of fuzzy time series from [17].

Definition 2.5: Assume that $Y(t)(t=\ldots, 0,1,2, \ldots)$ is a subset of real numbers and is the universe of discourse, and assume that fuzzy sets $\mu_{i}(t)(i=1,2, \ldots)$ are defined on $Y(t)$. Let $F(t)$ be a collection of $\mu_{i}(t)(i=1,2, \ldots)$. Then, $F(t)$ is called a fuzzy time series of $Y(t)(t=\ldots, 0,1,2, \ldots)$.

We can see that $F(t)$ is a function of time $t$, and $\mu_{i}(t)$ are linguistic values of $F(t)$, where $\mu_{i}(t)(i=1,2, \ldots)$ are represented by fuzzy sets. In [17], Song et al.divided the fuzzy time series into two categories which are the time-invariant fuzzy-time series and the time-variant fuzzy time series defined as follows.

Definition 2.6: If $F(t)$ is caused by $F(t-1)$ denoted by $F(t) \rightarrow F(t-1)$, then this relationship can be represented by

$$
F(t)=F(t-1) \circ R(t, t-1)
$$

where $R(t, t-1)$ is a fuzzy relationship between $F(t)$ and $F(t-$ 1 ) and is called the first-order model of $F(t)$.
Definition 2.7: Assume that $F(t)$ is a fuzzy time series, and $R(t, t-1)$ is a first-order model of $F(t)$. If $R(t, t-1)=R(t-$ $1, t-2)$ for any time $t$, then $F(t)$ is called the time-invariant fuzzy time series. If $R(t, t-1)$ is dependent on time $t$, that is $R(t, t-1)$ may be different from $R(t-1, t-2)$ for any $t$, then $F(t)$ is called the time-variant fuzzy time series.

In [18], Song and Chissom proposed the time-invariant fuzzy time series model. In [19], Song et al. proposed the time-variant fuzzy time series model. Both of these two models only used one factor to forecast the enrollments of the University of Alabama. In fact, an event may be influenced by many factors. In the following, we propose a new fuzzy time series called the two-factors fuzzy time series.

Definition 2.8: Assume that fuzzy time series $F(t)$ and $G(t)$ are the factors of the forecasting problems. If we only use $F(t)$ to solve the forecasting problems, then it is called a one-factor fuzzy time series. If we use both $F(t)$ and $G(t)$ to solve the forecasting problems, then it is called a two-factors fuzzy time series.

\section{A New FuZzy Time Series Model For TEMPERATURE PREDICTION}

In [7], we have presented a one-factor time-variant fuzzy time series model and proposed an algorithm (called Algorithm-A) for handling the forecasting problems. However, in the realworld, an event can be affected by many factors. For example, the temperature can be affected by the wind, the sunshine duration, the cloud density, the atmospheric pressure, ..., etc. If we only use one factor of them to forecast the temperature, the forecasting results may lack accuracy. We can get better forecasting results if we consider more factors for temperature prediction. In [4], [18], [19], and [21], the researchers only use the one-factor fuzzy time series model to deal with the forecasting problems. In this section, we propose a new forecasting model which is a two-factors time-variant fuzzy time series model. Based on the proposed model, we develop two algorithms which use two factors (i.e., the daily average temperature and the daily cloud density) for temperature prediction.

Definition 3.1: Assume that $Y(t)(t=\ldots, 0,1,2, \ldots)$ is a subset of $R$ and is the universe of discourse. Let $F(t)$ and $G(t)(t=1,2, \ldots)$ be two fuzzy time series on $Y(t)$, where $F(t)=\left\{\mu_{11}(t), \mu_{12}(t), \ldots, \mu_{1 n}(t)\right\}$, $G(t)=\left\{\mu_{21}(t), \mu_{22}(t), \ldots, \mu_{2 n}(t)\right\}, \mu_{1 i}(t)$ is a fuzzy set on $Y(t), \mu_{2 i}(t)$ is a fuzzy set on $Y(t)$, and $1 \leq i \leq n$. Assume that we want to forecast $F(t)$ and use $G(t)$ to aid the forecasting of $F(t)$, then $F(t)$ and $G(t)$ are called the main-factor fuzzy time series and the second-factor fuzzy time series of the two-factors time-variant fuzzy time series model, respectively.

For example, in the proposed two-factors time-variant fuzzy time series model for temperature prediction, "the daily average temperature" and "the daily cloud density" are called the main-factor and the second-factor of the two-factors time-variant fuzzy time series model, respectively.

The fuzzified variation $f(t)$ of the main-factor fuzzy time series $F(t)$ between time $t$ and time $t-1$ can be described as follows. Assume that the universe of discourse $U$ has been 
divided into $m$ intervals (i.e., $u_{1}, u_{2}, \ldots$, and $u_{m}$ ). Furthermore, assume that there are $k$ linguistic terms (i.e., $A_{1}, A_{2}, \ldots$, and $A_{k}$ ) described by fuzzy sets shown as follows:

$$
\begin{gathered}
A_{1}=\mu_{A 1}\left(u_{1}\right) / u_{1}+\mu_{A 1}\left(u_{2}\right) / u_{2}+\cdots+\mu_{A 1}\left(u_{m}\right) / u_{m} \\
A_{2}=\mu_{A 2}\left(u_{1}\right) / u_{1}+\mu_{A 2}\left(u_{2}\right) / u_{2}+\cdots+\mu_{A 2}\left(u_{m}\right) / u_{m} . \\
\vdots \\
A_{k}=\mu_{A k}\left(u_{1}\right) / u_{1}+\mu_{A k}\left(u_{2}\right) / u_{2}+\cdots+\mu_{A k}\left(u_{m}\right) / u_{m}
\end{gathered}
$$

where the maximum membership value of $A_{i}$ occurs at $u_{i}$ and $1 \leq i \leq k$. If the difference of the historical data of the mainfactor fuzzy time series $F(t)$ between time $t$ and time $t-1$ is $x$ and $x \in u_{i}$, then the fuzzified variation $f(t)$ of the historical data of the main-factor fuzzy time series $F(t)$ between time $t$ and time $t-1$ is $A_{i}$, where $1 \leq i \leq k$. That is,

$$
f(t)=\left[\begin{array}{llll}
\mu_{A i}\left(u_{1}\right) & \mu_{A i}\left(u_{2}\right) & \cdots & \mu_{A i}\left(u_{m}\right)
\end{array}\right] .
$$

The fuzzified data $g(t)$ of the second-factor fuzzy times series $G(t)$ at time $t$ can be described as follows. Assume that there are $k$ linguistic terms (i.e., $B_{1}, B_{2}, \ldots$, and $B_{k}$ ) represented by fuzzy sets to describe the fuzzified historical data of the secondfactor "the daily cloud density", where the daily cloud density ranges from $0 \%$ to $100 \%$

$$
\begin{gathered}
B_{1}=\mu_{B 1}\left(u_{1}\right) / u_{1}+\mu_{B 1}\left(u_{2}\right) / u_{2}+\cdots+\mu_{B 1}\left(u_{m}\right) / u_{m} \\
B_{2}=\mu_{B 2}\left(u_{1}\right) / u_{1}+\mu_{B 2}\left(u_{2}\right) / u_{2}+\cdots+\mu_{B 2}\left(u_{m}\right) / u_{m} \\
\vdots \\
B_{k}=\mu_{B k}\left(u_{1}\right) / u_{1}+\mu_{B k}\left(u_{2}\right) / u_{2}+\cdots+\mu_{B k}\left(u_{m}\right) / u_{m} .
\end{gathered}
$$

If the data $y$ of the second-factor fuzzy time series $\in(90,100]$, then the fuzzified data of $y$ is $B_{1}$. If $y \in[75,90)$, then the fuzzified data of $y$ is $B_{2}$. If $y \in[60,75)$, then the fuzzified data of $y$ is $B_{3}$. If $y \in[45,60)$, then the fuzzified data of $y$ is $B_{4}$. If $y \in[30,45)$, then the fuzzified data of $y$ is $B_{5}$. If $y \in[15,30)$, then the fuzzified data of $y$ is $B_{6}$. If $y \in[0,15)$, then the fuzzified data of $y$ is $B_{7}$.

To forecast the data of time $t$, we must decide the window basis $w$. Then, we can get the criterion vector $C(t)$ and the operation matrix $O^{w}(t)$ at time $t$ which are expressed as follows:

$$
\begin{aligned}
& C(t)=f(t-1)=\left[\begin{array}{llll}
C_{1} & C_{2} & \cdots & C_{m}
\end{array}\right] \\
& O^{w}(t)=\left[\begin{array}{c}
f(t-2) \\
f(t-3) \\
\vdots \\
f(t-w)
\end{array}\right] \\
& =\left[\begin{array}{cccc}
O_{11} & O_{12} & \cdots & O_{1 m} \\
O_{21} & O_{22} & \cdots & O_{2 m} \\
\vdots & \vdots & \vdots & \vdots \\
O_{(w-1) 1} & O_{(w-1) 2} & \cdots & O_{(w-1) m}
\end{array}\right]
\end{aligned}
$$

\begin{tabular}{|c|c|c|c|c|}
\hline Day Month & June & July & August & September \\
\hline 1 & 26.1 & 29.9 & 27.1 & 27.5 \\
\hline 2 & 27.6 & 28.4 & 28.9 & 26.8 \\
\hline 3 & 29.0 & 29.2 & 28.9 & 26.4 \\
\hline 4 & 30.5 & 29.4 & 29.3 & 27.5 \\
\hline 5 & 30.0 & 29.9 & 28.8 & 26.6 \\
\hline 6 & 29.5 & 29.6 & 28.7 & 28.2 \\
\hline 7 & 29.7 & 30.1 & 29.0 & 29.2 \\
\hline 8 & 29.4 & 29.3 & 28.2 & 29.0 \\
\hline 9 & 28.8 & 28.1 & 27.0 & 30.3 \\
\hline 10 & 29.4 & 28.9 & 28.3 & 29.9 \\
\hline 11 & 29.3 & 28.4 & 28.9 & 29.9 \\
\hline 12 & 28.5 & 29.6 & 28.1 & 30.5 \\
\hline 13 & 28.7 & 27.8 & 29.9 & 30.2 \\
\hline 14 & 27.5 & 29.1 & 27.6 & 30.3 \\
\hline 15 & 29.5 & 27.7 & 26.8 & 29.5 \\
\hline 16 & 28.8 & 28.1 & 27.6 & 28.3 \\
\hline 17 & 29.0 & 28.7 & 27.9 & 28.6 \\
\hline 18 & 30.3 & 29.9 & 29.0 & 28.1 \\
\hline 19 & 30.2 & 30.8 & 29.2 & 28.4 \\
\hline 20 & 30.9 & 31.6 & 29.8 & 28.3 \\
\hline 21 & 30.8 & 31.4 & 29.6 & 26.4 \\
\hline 22 & 28.7 & 31.3 & 29.3 & 25.7 \\
\hline 23 & 27.8 & 31.3 & 28.0 & 25.0 \\
\hline 24 & 27.4 & 31.3 & 28.3 & 27.0 \\
\hline 25 & 27.7 & 28.9 & 28.6 & 25.8 \\
\hline 26 & 27.1 & 28.0 & 28.7 & 26.4 \\
\hline 27 & 28.4 & 28.6 & 29.0 & 25.6 \\
\hline 28 & 27.8 & 28.0 & 27.7 & 24.2 \\
\hline 29 & 29.0 & 29.3 & 26.2 & 23.3 \\
\hline 30 & 30.2 & 27.9 & 26.0 & 23.5 \\
\hline 31 & & 26.9 & 27.7 & \\
\hline
\end{tabular}

where $f(t-1)$ is the fuzzified variation of the main-factor fuzzy time series $F(t)$ between time $t-1$ and time $t-2, m$ is the
TABLE I

Historical DATA OF THE DAILY AVERAGE TEMPERATURE FROM JUNE 1996 TO SEPTEMBER 1996 IN TAIPEI (UNIT: $\left.{ }^{\circ} \mathrm{C}\right)[2]$

number of elements in the universe of discourse, $C_{j}$ and $O_{i j}$ are crisp values, $0 \leq C_{j} \leq 1,0 \leq O_{i j} \leq 1,1 \leq i \leq w-1$, and $1 \leq j \leq m$.

From (9) and (10), we can see that both the criterion vector $C(t)$ and the operation vector $O^{w}(t)$ are caused by the mainfactor fuzzy time series $F(t)$. In the following, we define the second-factor vector $S(t)$ which is composed by the secondfactor fuzzy time series $G(t)$.

Definition 3.2: Let $G(t)$ be a second-factor fuzzy time series in the universe of discourse. The second-factor vector $S(t)$ is described by

$$
S(t)=g(t-1)=\left[\begin{array}{llll}
S_{1} & S_{2} & \cdots & S_{m}
\end{array}\right]
$$

where $S(t)$ is the second-factor vector at time $t, g(t-1)$ is the fuzzified data of the second-factor fuzzy time series $G(t)$ at time $t-1, m$ is the number of elements in the universe of discourse, $S_{i} \in[0,1]$, and $1 \leq i \leq m$.

The fuzzy relationship of the one-factor time-variant fuzzy time series model is the relationship between the operation matrix and the criterion matrix. In the two-factors time-variant fuzzy time series model, we must decide the fuzzy relationship between the criterion vector, the operation matrix, and the second-factor vector. The new fuzzy relationship matrix is defined as follows.

Definition 3.3: Assume that $F(t)$ is the main-factor fuzzy time series and $G(t)$ is the second-factor fuzzy time series, $C(t)$ is a criterion vector on $F(t), O^{w}(t)$ is an operation matrix on $F(t)$, and $S(t)$ is a second-factor vector on $G(t)$. The fuzzy re- 
TABLE II

Historical Data of the Daily Cloud Density From June 1996 to SEPTEMBER 1996 IN TAIPEI (UNIT: \%) [2]

\begin{tabular}{|c|c|c|c|c|}
\hline Day Month & June & July & August & September \\
\hline 1 & 36 & 15 & 100 & 29 \\
\hline 2 & 23 & 31 & 78 & 53 \\
\hline 3 & 23 & 26 & 68 & 66 \\
\hline 4 & 10 & 34 & 44 & 50 \\
\hline 5 & 13 & 24 & 56 & 53 \\
\hline 6 & 30 & 28 & 89 & 63 \\
\hline 7 & 45 & 50 & 71 & 36 \\
\hline 8 & 35 & 34 & 28 & 76 \\
\hline 9 & 26 & 15 & 70 & 55 \\
\hline 10 & 21 & 8 & 44 & 31 \\
\hline 11 & 43 & 36 & 48 & 31 \\
\hline 12 & 40 & 13 & 76 & 25 \\
\hline 13 & 30 & 26 & 50 & 14 \\
\hline 14 & 29 & 44 & 84 & 45 \\
\hline 15 & 30 & 25 & 69 & 38 \\
\hline 16 & 46 & 24 & 78 & 24 \\
\hline 17 & 55 & 26 & 39 & 19 \\
\hline 18 & 19 & 25 & 20 & 39 \\
\hline 19 & 15 & 21 & 24 & 14 \\
\hline 20 & 56 & 35 & 25 & 3 \\
\hline 21 & 60 & 29 & 19 & 38 \\
\hline 22 & 96 & 48 & 46 & 70 \\
\hline 23 & 63 & 53 & 41 & 71 \\
\hline 24 & 28 & 44 & 34 & 70 \\
\hline 25 & 14 & 100 & 29 & 40 \\
\hline 26 & 25 & 100 & 31 & 30 \\
\hline 27 & 29 & 91 & 41 & 34 \\
\hline 28 & 55 & 84 & 14 & 59 \\
\hline 29 & 29 & 38 & 28 & 83 \\
\hline 30 & 19 & 46 & 33 & 38 \\
\hline 31 & & 95 & 26 & \\
\hline
\end{tabular}

lationship matrix $R(t)$ between $C(t), O^{w}(t)$, and $S(t)$ is equal to $R(t)=O^{w}(t) \otimes S(t) \otimes C(t)$, where we have (12), shown at the bottom of the page. $m$ is the number of elements in the universe of discourse, $R_{i j}=O_{i j} \times S_{j} \times C_{j}, 1 \leq i \leq w-1$, $1 \leq j \leq m$, and " $\times$ " is the multiplication operator.

From the fuzzy relationship matrix $R(t)$, we can get the fuzzified forecasted variation $f(t)$ between time $t$ and time $t-1$ described by

$$
\begin{aligned}
f(t)= & {\left[\operatorname{Max}\left(R_{11}, R_{21}, \ldots, R_{(w-1) 1}\right)\right.} \\
& \operatorname{Max}\left(R_{12}, R_{22}, \ldots, R_{(w-1) 2}\right) \\
& \left.\cdots \quad \operatorname{Max}\left(R_{1 m}, R_{2 m}, \ldots, R_{(w-1) m}\right)\right]
\end{aligned}
$$

where $f(t)$ is the fuzzified variation of the fuzzy time series $F(t)$ between time $t$ and time $t-1$.
TABLE III

FuZZIFIED Historical Data OF THE MAIN-FACTOR (THE DAILY AVERAGE Temperature) AND the SECOND-FACTOR (THE DAILy Cloud Density) IN JUNE 1996 IN TAIPEI

\begin{tabular}{l|cccc}
\hline Day & $\begin{array}{l}\text { Variation of the } \\
\text { Main-Factor } \\
\text { (Unit: }{ }^{\circ} \text { C) }\end{array}$ & $\begin{array}{l}\text { Fuzzified Variation } \\
\text { of the Main-Factor }\end{array}$ & $\begin{array}{l}\text { Data of the } \\
\text { Second-Factor } \\
\text { (Unit: \%) }\end{array}$ & $\begin{array}{l}\text { Fuzzified Data of } \\
\text { the Second-Factor }\end{array}$ \\
\hline 1 & & & 36 & $\mathrm{~B}_{5}$ \\
2 & 1.5 & $\mathrm{~A}_{7}$ & 23 & $\mathrm{~B}_{6}$ \\
3 & 1.4 & $\mathrm{~A}_{6}$ & 23 & $\mathrm{~B}_{6}$ \\
4 & 1.5 & $\mathrm{~A}_{7}$ & 10 & $\mathrm{~B}_{7}$ \\
5 & -0.5 & $\mathrm{~A}_{3}$ & 13 & $\mathrm{~B}_{7}$ \\
6 & -0.5 & $\mathrm{~A}_{3}$ & 30 & $\mathrm{~B}_{5}$ \\
7 & 0.2 & $\mathrm{~A}_{4}$ & 45 & $\mathrm{~B}_{4}$ \\
8 & -0.3 & $\mathrm{~A}_{4}$ & 35 & $\mathrm{~B}_{5}$ \\
9 & -0.6 & $\mathrm{~A}_{3}$ & 26 & $\mathrm{~B}_{6}$ \\
10 & 0.6 & $\mathrm{~A}_{5}$ & 21 & $\mathrm{~B}_{6}$ \\
11 & -0.1 & $\mathrm{~A}_{4}$ & 43 & $\mathrm{~B}_{5}$ \\
12 & -0.8 & $\mathrm{~A}_{3}$ & 40 & $\mathrm{~B}_{5}$ \\
13 & 0.2 & $\mathrm{~A}_{4}$ & 30 & $\mathrm{~B}_{5}$ \\
14 & -1.2 & $\mathrm{~A}_{2}$ & 29 & $\mathrm{~B}_{6}$ \\
15 & 2.0 & $\mathrm{~A}_{7}$ & 30 & $\mathrm{~B}_{5}$ \\
16 & -0.7 & $\mathrm{~A}_{3}$ & 46 & $\mathrm{~B}_{4}$ \\
17 & 0.2 & $\mathrm{~A}_{4}$ & 55 & $\mathrm{~B}_{4}$ \\
18 & 1.3 & $\mathrm{~A}_{6}$ & 19 & $\mathrm{~B}_{6}$ \\
19 & -0.1 & $\mathrm{~A}_{4}$ & 15 & $\mathrm{~B}_{6}$ \\
20 & 0.7 & $\mathrm{~A}_{5}$ & 56 & $\mathrm{~B}_{4}$ \\
21 & -0.1 & $\mathrm{~A}_{4}$ & 60 & $\mathrm{~B}_{3}$ \\
22 & -2.1 & $\mathrm{~A}_{1}$ & 96 & $\mathrm{~B}_{1}$ \\
23 & -0.9 & $\mathrm{~A}_{3}$ & 63 & $\mathrm{~B}_{3}$ \\
24 & -0.4 & $\mathrm{~A}_{3}$ & 28 & $\mathrm{~B}_{6}$ \\
25 & 0.3 & $\mathrm{~A}_{5}$ & 14 & $\mathrm{~B}_{7}$ \\
26 & -0.6 & $\mathrm{~A}_{3}$ & 25 & $\mathrm{~B}_{6}$ \\
27 & 1.3 & $\mathrm{~A}_{6}$ & 29 & $\mathrm{~B}_{6}$ \\
28 & -0.6 & $\mathrm{~A}_{3}$ & 55 & $\mathrm{~B}_{6}$ \\
29 & 1.2 & $\mathrm{~A}_{6}$ & 29 & $\mathrm{~B}_{6}$ \\
30 & 1.2 & $\mathrm{~A}_{6}$ & 19 & \\
\hline
\end{tabular}

In the following, we propose a new algorithm called Algorithm-B based on the proposed two-factors time-variant fuzzy time series model and we will use two factors (i.e., the daily average temperature and the daily cloud density) for temperature prediction from June 1996 to September 1996 in Taipei, Taiwan, where "the daily average temperature" and "the daily cloud density" are called the main-factor and the second-factor of the two-factors time-variant fuzzy time series model, respectively. The algorithm is now presented as follows.

\section{Algorithm-B:}

Step 1) Partition the historical data into suitable groups and perform the following forecasting steps to each group, respectively. For example, we partition the historical data into four groups, i.e., June, July, August, and September, as shown in Table I.

$$
\begin{aligned}
R(t) & =\left[\begin{array}{cccc}
O_{11} \times S_{1} \times C_{1} & O_{12} \times S_{2} \times C_{2} & \cdots & O_{1 m} \times S_{m} \times C_{m} \\
O_{21} \times S_{1} \times C_{1} & O_{22} \times S_{2} \times C_{2} & \cdots & O_{2 m} \times S_{m} \times C_{m} \\
\vdots & \vdots & \vdots & \vdots \\
O_{(w-1) 1} \times S_{1} \times C_{1} & O_{(w-1) 2} \times S_{2} \times C_{2} & \cdots & O_{(w-1) m} \times S_{m} \times C_{m}
\end{array}\right] \\
& =\left[\begin{array}{cccc}
R_{11} & R_{12} & \cdots & R_{1 m} \\
R_{21} & R_{22} & \cdots & R_{2 m} \\
\vdots & \vdots & \vdots & \vdots \\
R_{(w-1) 1} & R_{(w-1) 2} & \cdots & R_{(w-1) m}
\end{array}\right]
\end{aligned}
$$




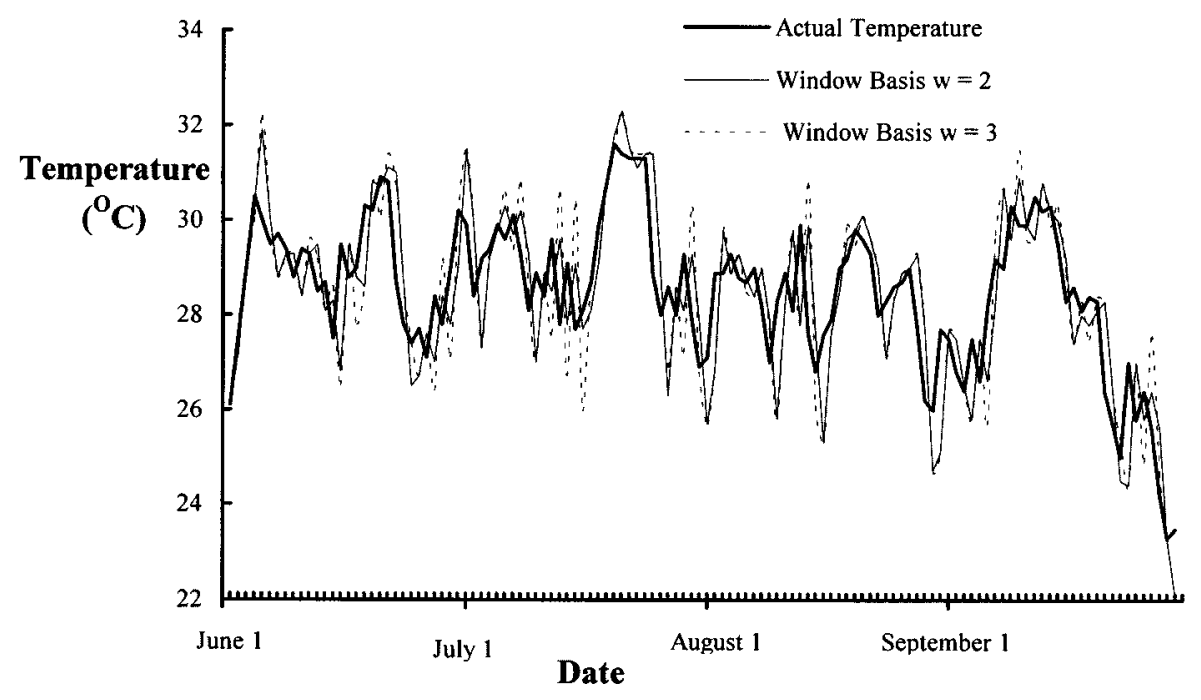

Fig. 1. Curve of the actual temperature and forecasted temperature of Algorithm-A with the window bases $w=2$ and $w=3$.

Step 2) Compute the variations of the main-factor fuzzy time series between any two continuous data. Find the maximum decrease $D_{L}$ and the maximum increase $D_{R}$ between any two continuous data, and define the universe of discourse $U, U=\left[D_{L}-D_{1}, D_{R}+D_{2}\right]$, where $D_{1}$ and $D_{2}$ are suitable positive numbers. For example, assume that we want to forecast the temperature of June 1996 in Taipei. From Table I, we can see that $D_{L}=-2.1$, and $D_{R}=2.0$. We set $D_{1}=0.1, D_{2}=0$. Then, the universe of discourse can be defined as $U=[-2.2,2.0]$.

Step 3) Partition the universe of discourse $U$ into several even length intervals $u_{1}, u_{2}, \ldots, u_{m}$. For example, in this case, we partition the universe of discourse $U$ into seven intervals $u_{1}, u_{2}, \ldots, u_{7}$, where $u_{1}=[-2.2,-1.6], u_{2}=[-1.6,-1.0]$, $u_{3}=[-1.0,-0.4], u_{4}=[-0.4,0.2]$, $u_{5}=[0.2,0.8], u_{6}=[0.8,1.4]$, and $u_{7}=[1.4,2.0]$.

Step 4) Define fuzzy sets on the universe of discourse $U$ for the fuzzified variation of the main-factor fuzzy time series $F(t)$. In this case, we consider seven fuzzy sets which are $A_{1}=$ (very big decrease), $A_{2}=$ (big decrease $), A_{3}=$ (decrease), $A_{4}=$ (no change), $A_{5}=$ (increase), $A_{6}=$ (big increase), $A_{7}=$ (very big increase), where the fuzzy sets $A_{1}, A_{2}, \ldots$, and $A_{7}$ in the universe of discourse $U$ are defined as follows:

$A_{1}=1 / u_{1}+0.5 / u_{2}+0 / u_{3}+0 / u_{4}+0 / u_{5}+0 / u_{6}+0 / u_{7}$, $A_{2}=0.5 / u_{1}+1 / u_{2}+0.5 / u_{3}+0 / u_{4}+0 / u_{5}+0 / u_{6}+0 / u_{7}$, $A_{3}=0 / u_{1}+0.5 / u_{2}+1 / u_{3}+0.5 / u_{4}+0 / u_{5}+0 / u_{6}+0 / u_{7}$, $A_{4}=0 / u_{1}+0 / u_{2}+0.5 / u_{3}+1 / u_{4}+0.5 / u_{5}+0 / u_{6}+0 / u_{7}$, $A_{5}=0 / u_{1}+0 / u_{2}+0 / u_{3}+0.5 / u_{4}+1 / u_{5}+0.5 / u_{6}+0 / u_{7}$, $A_{6}=0 / u_{1}+0 / u_{2}+0 / u_{3}+0 / u_{4}+0.5 / u_{5}+1 / u_{6}+0.5 / u_{7}$, $A_{7}=0 / u_{1}+0 / u_{2}+0 / u_{3}+0 / u_{4}+0 / u_{5}+0.5 / u_{6}+1 / u_{7}$.
Step 5) Define fuzzy sets on the universe of discourse $U$ for the second-factor fuzzy time series $G(t)$. In this case, the second-factor fuzzy time series is the daily cloud density which ranges from $0 \%$ to $100 \%$ as shown in Table II. We consider seven fuzzy sets which are $B_{1}=$ (very, very cloudy), $B_{2}=$ (very cloudy), $B_{3}=$ (more or less cloudy), $B_{4}=$ (cloudy), $B_{5}=$ (little cloudy), $B_{6}=$ (very little cloudy), $B_{7}=$ (very very little cloudy) for the second-factor fuzzy time series. We describe some human knowledge as follows.

1) When the cloud density increases, it seems that the weather becomes bad and the temperature may go down. When the cloud density decreases, it seems that the weather becomes good and the temperature may go up.

2) When yesterday's cloud density was very low, that means that yesterday was a sunny day. It is more likely that today's cloud density will increase and it is less likely that the cloud density will decrease. Thus, a decrease of the temperature has a higher possibility than an increase of the temperature.

3) When yesterday's cloud density was very high, that means that yesterday was a cloudy day. It is more likely that today's cloud density will decrease and it is less likely that the cloud density will increase. Thus, an increase of the temperature has a higher possibility than a decrease of the temperature.

According to the human knowledge described above, we can define fuzzy sets $B_{1}, B_{2}, \ldots, B_{7}$ on the universe of discourse $U, U=\left\{u_{1}, u_{2}, \ldots, u_{7}\right\}$, as follows:

$$
B_{1}=0 / u_{1}+0 / u_{2}+0.5 / u_{3}+1 / u_{4}+1 / u_{5}+1 / u_{6}+1 / u_{7},
$$$$
B_{2}=0 / u_{1}+0.5 / u_{2}+1 / u_{3}+1 / u_{4}+1 / u_{5}+1 / u_{6}+1 / u_{7} \text {, }
$$ 


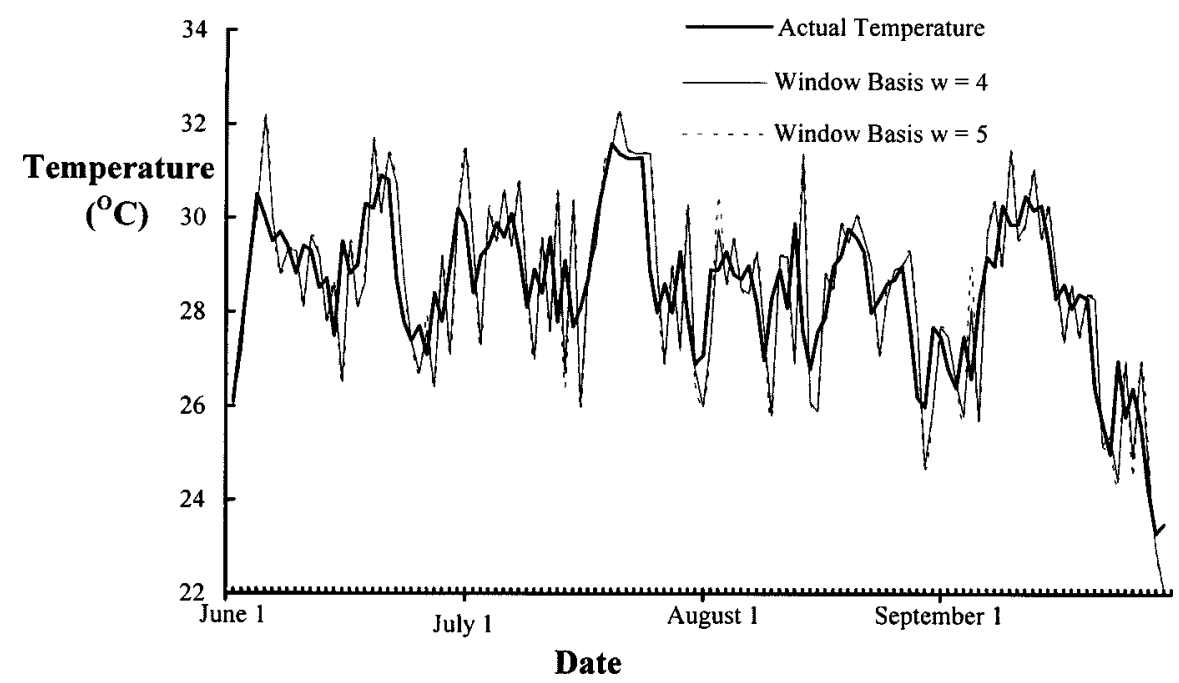

Fig. 2. Curve of the actual temperature and forecasted temperature of Algorithm-A with the window bases $w=4$ and $w=5$.

$$
\begin{aligned}
& B_{3}=0.5 / u_{1}+1 / u_{2}+1 / u_{3}+1 / u_{4}+1 / u_{5}+1 / u_{6}+1 / u_{7}, \\
& B_{4}=1 / u_{1}+1 / u_{2}+1 / u_{3}+1 / u_{4}+1 / u_{5}+1 / u_{6}+1 / u_{7}, \\
& B_{5}=1 / u_{1}+1 / u_{2}+1 / u_{3}+1 / u_{4}+1 / u_{5}+1 / u_{6}+0.5 / u_{7}, \\
& B_{6}=1 / u_{1}+1 / u_{2}+1 / u_{3}+1 / u_{4}+1 / u_{5}+0.5 / u_{6}+0 / u_{7}, \\
& B_{7}=1 / u_{1}+1 / u_{2}+1 / u_{3}+1 / u_{4}+0.5 / u_{5}+0 / u_{6}+0 / u_{7} .
\end{aligned}
$$

Step 6) Fuzzify the variation of the main-factor (i.e., the daily average temperature) fuzzy time series and fuzzify the data of the second-factor (i.e., the cloud density) fuzzy time series. The fuzzification method is described as follows:

1) Assume that the variation $p$ of the main-factor fuzzy time series belongs to the interval $u_{i}$ (i.e., $p \in u_{i}$ ), and assume that, from (14), we know that the maximum membership value of fuzzy set $A_{j}$ occured at $u_{i}$, then the fuzzified variation of $p$ is $A_{j}$.

2) If the data $y$ of the second-factor fuzzy time series $\in[90,100]$, then the fuzzified data of $y$ is $B_{1}$. If $y \in[75,90)$, then the fuzzified data of $y$ is $B_{2}$. If $y \in[60,75)$, then the fuzzified data of $y$ is $B_{3}$. If $y \in[45,60)$, then the fuzzified data of $y$ is $B_{4}$. If $y \in[30,45)$, then the fuzzified data of $y$ is $B_{5}$. If $y \in[15,30)$, then the fuzzified data of $y$ is $B_{6}$. If $y \in[0,15)$, then the fuzzified data of $y$ is $B_{7}$. For example, the fuzzified variation of the main-factor (i.e., the daily average temperature) fuzzy time series and the fuzzified data of the second-factor (i.e., the cloud density) fuzzy time series in June 1996 in Taipei are shown in Table III.

Step 7) Choose a suitable window basis $w$ and define the criterion vector $C(t)$, the operation matrix $O^{w}(t)$, and the second-factor vector $S(t)$. Then, calculate the fuzzy relationship matrix $R(t)$ between the criterion vector $C(t)$, the operation matrix $O^{w}(t)$, and the second-factor vector $S(t)$ based on (12), where t is the date for which we want to forecast the temperature. From the fuzzy relationship matrix $R(t)$, we can get the fuzzified forecasted variation $f(t)$ based on (13). Then, we can evaluate the fuzzified forecasted output. For example, if we set window basis $w=4$, and we want to forecast the average temperature for June 15, 1996, in Taipei. Then, we can set a $3 \times 7$ operation matrix $O^{4}(t)$, a $1 \times 7$ second-factor vector $S(t)$, and a $1 \times 7$ criterion vector $C(t)$ shown as follows ${ }^{1}$ :

$O^{4}$ (June 15, 1996)

$=\left[\begin{array}{l}\text { fuzzy variation of the main-factor of June } 13,1996 \\ \text { fuzzy variation of the main-factor of June 12,1996 } \\ \text { fuzzy variation of the main-factor of June 11, } 1996\end{array}\right]$

\begin{tabular}{|c|c|c|c|c|c|c|}
\hline (VBD) & (BD) & (D) & (NC) & (I) & (BI) & (VBI) \\
\hline$=[1$ & 1 & 1 & 1 & 1 & 0.5 & 0 \\
\hline
\end{tabular}

$=\left[\begin{array}{l}A_{4} \\ A_{3} \\ A_{4}\end{array}\right]$

$=\left[\begin{array}{ccccccc}0 & 0 & 0.5 & 1 & 0.5 & 0 & 0 \\ 0 & 0.5 & 1 & 0.5 & 0 & 0 & 0 \\ 0 & 0 & 0.5 & 1 & 0.5 & 0 & 0\end{array}\right]$

$S($ June 15,1996$)=$ fuzzy data of the second-factor

\begin{tabular}{|c|c|c|c|c|c|c|}
\hline (VBD) & (BD) & (D) & (NC) & (I) & (BI) & (VBI) \\
\hline$=[0.5$ & 1 & 0.5 & 0 & 0 & 0 & \\
\hline
\end{tabular}
of June 14, $1996=\left[B_{6}\right]$ $C$ (June 15,1996$)=$ fuzzy variation of the mainfactor of June 14, $1996=\left[A_{2}\right]$

Calculate the relation matrix $R(t)$ by $R(t)[i, j]=$ $O^{4}(t)[i, j] \otimes S(t)[j] \otimes C(t)[j]$, where $1 \leq i \leq 3$, and $1 \leq j \leq 7$. Then, based on (12), we can get

$$
R(\text { June } 15,1996)=\left[\begin{array}{ccccccc}
0 & 0 & 0.25 & 0 & 0 & 0 & 0 \\
0 & 0.5 & 0.5 & 0 & 0 & 0 & 0 \\
0 & 0 & 0.25 & 0 & 0 & 0 & 0
\end{array}\right]
$$

${ }^{1}$ In Step 7, the following abbreviations are used: $\mathrm{VBD}=$ very big decrease; $\mathrm{BD}=$ big decrease; $\mathrm{D}=$ decrease; $\mathrm{NC}=$ no change $\mathrm{I}=$ increase; $\mathrm{BI}=$ big increase; and $\mathrm{VBI}=$ very big increase. 


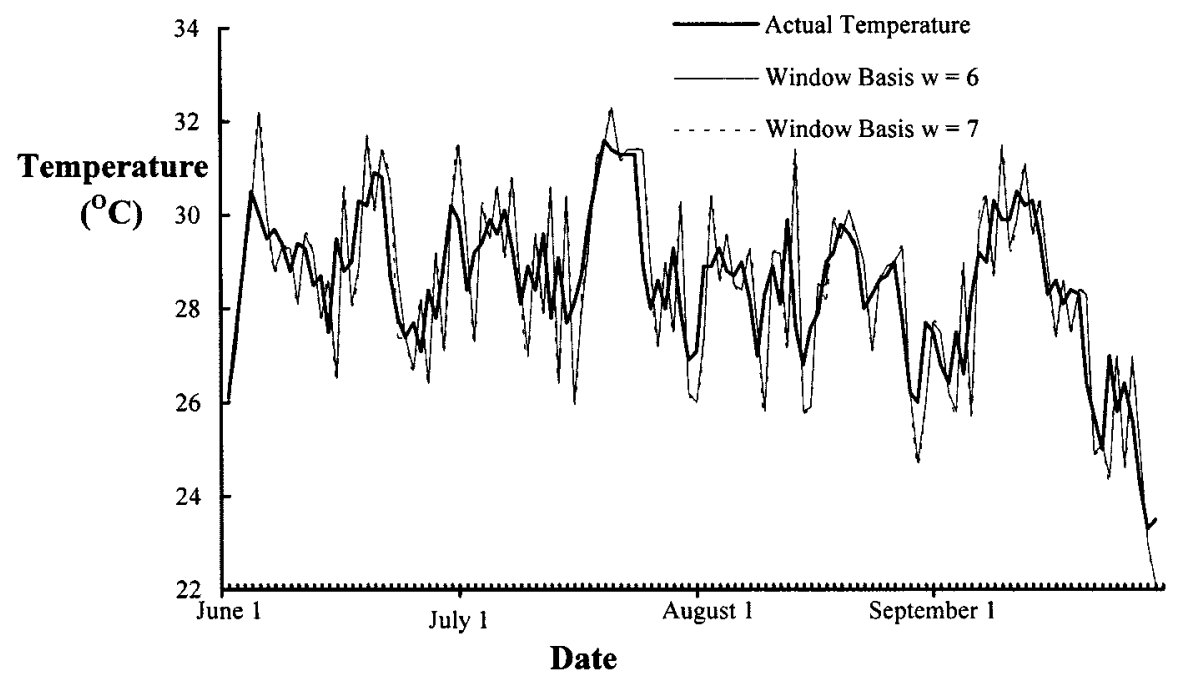

Fig. 3. Curve of the actual temperature and forecasted temperature of Algorithm-A with the window bases $w=6$ and $w=7$.

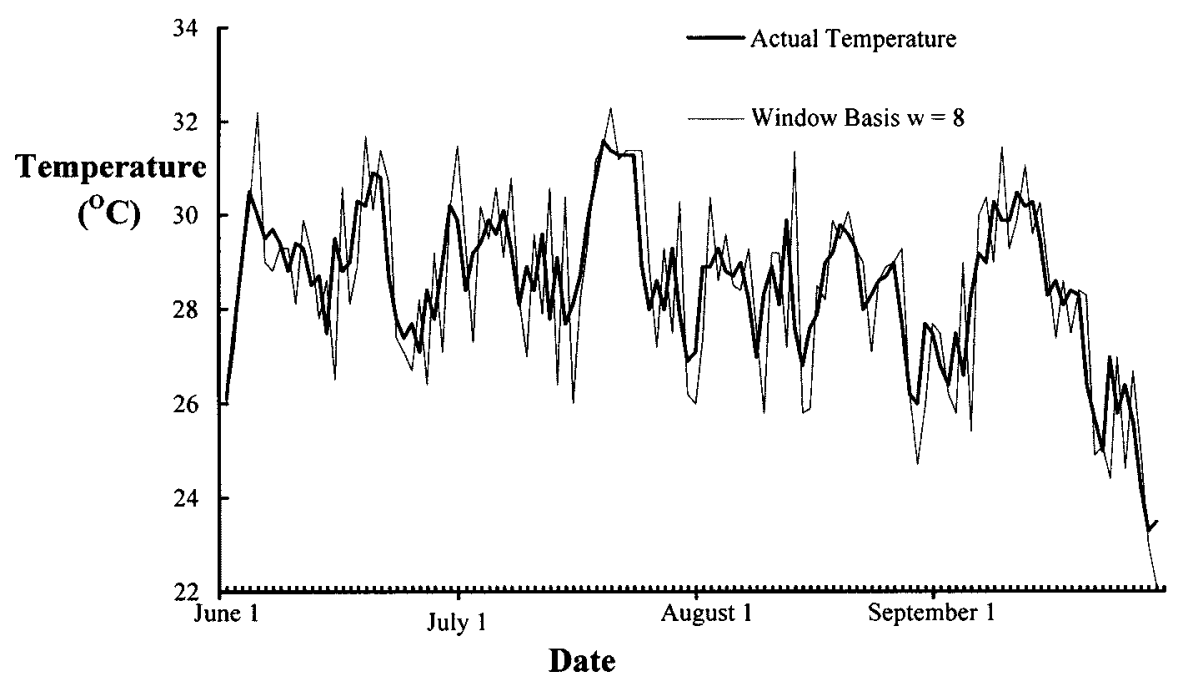

Fig. 4. Curve of the actual temperature and forecasted temperature of Algorithm-A with the window bases $w=8$.

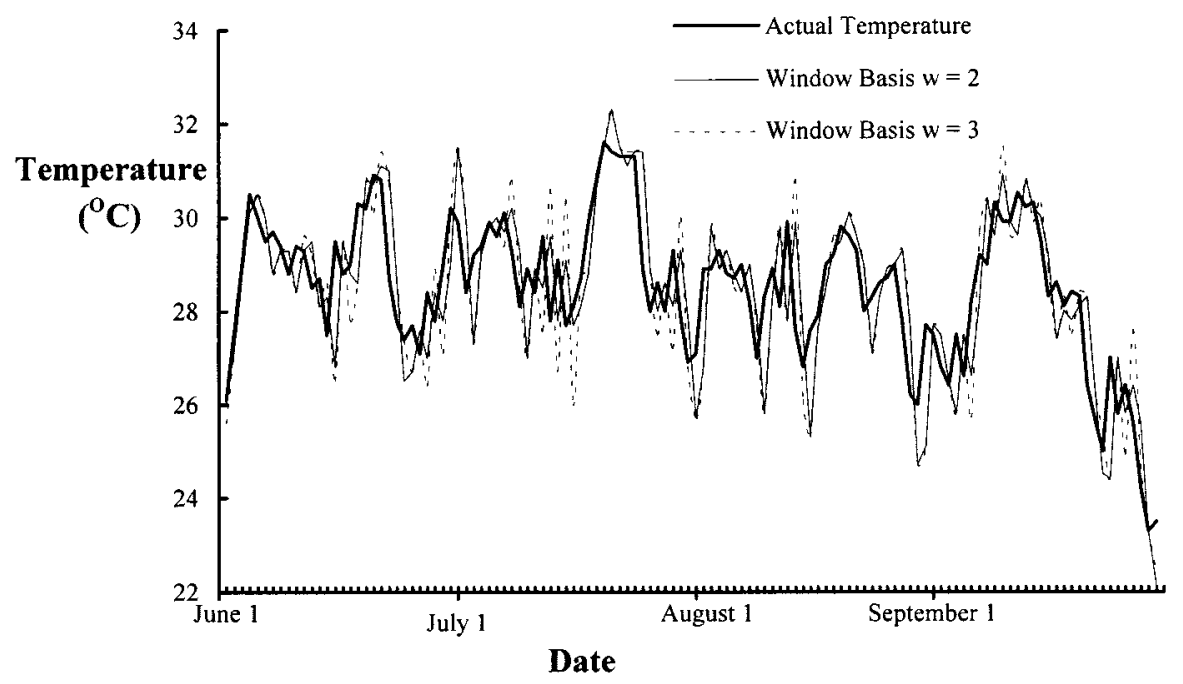

Fig. 5. Curve of the actual temperature and forecasted temperature of Algorithm-B with the window bases $w=2$ and $w=3$. 


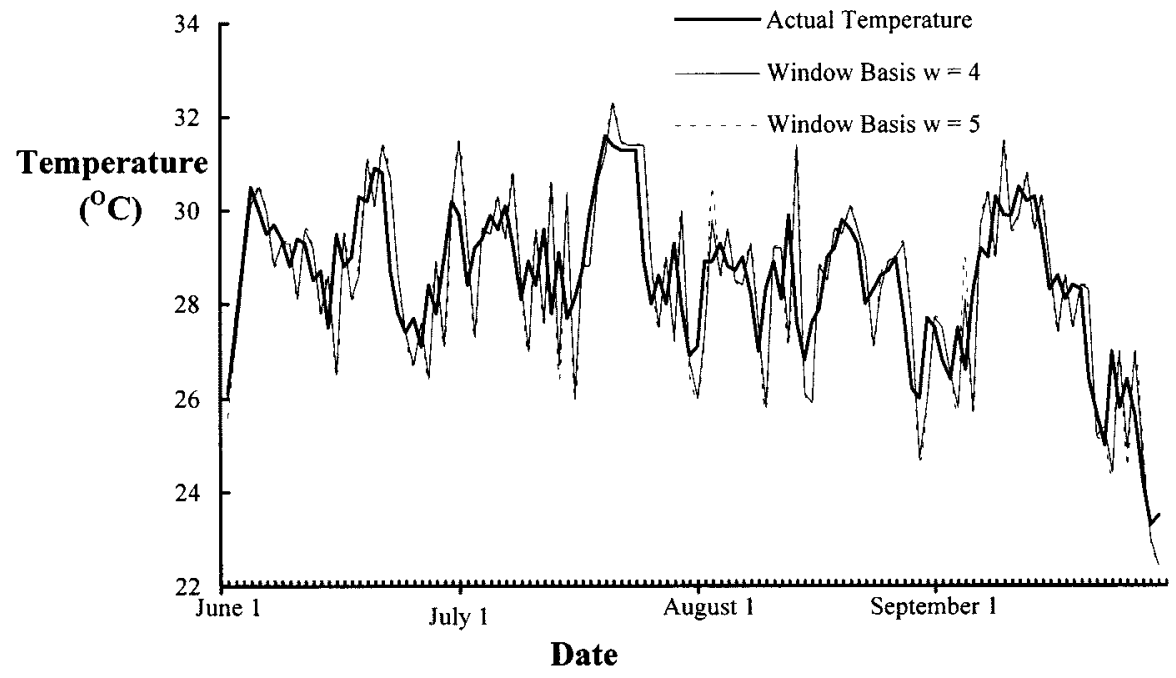

Fig. 6. Curve of the actual temperature and forecasted temperature of Algorithm-B with the window bases $w=4$ and $w=5$.

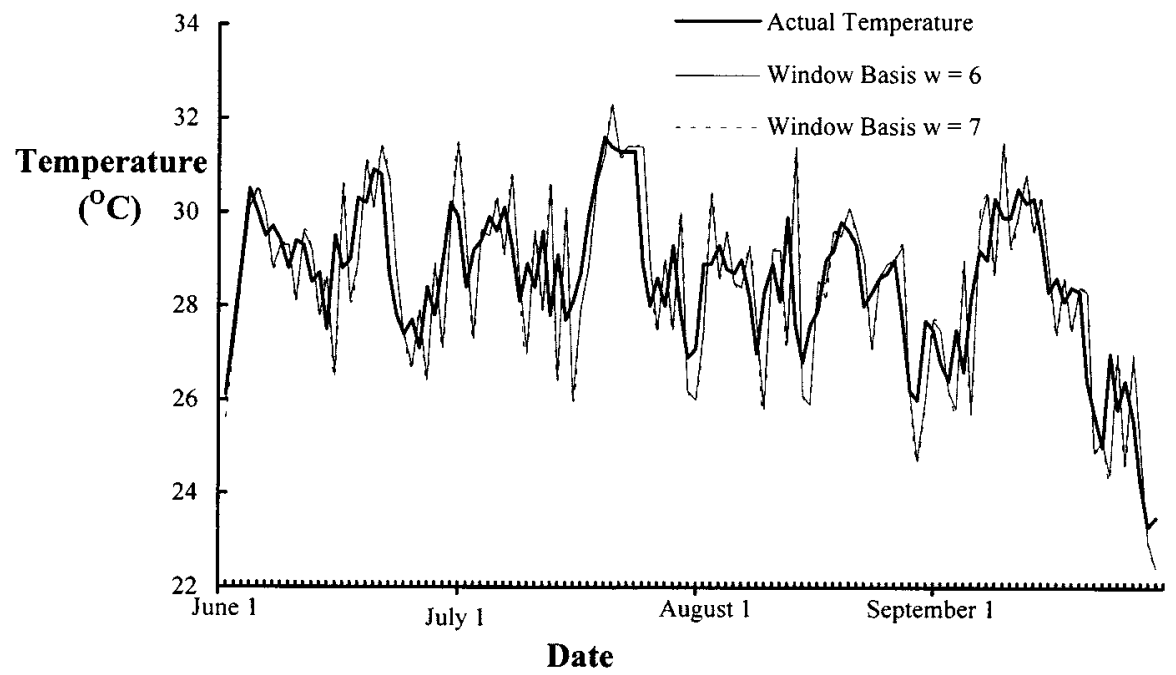

Fig. 7. Curve of the actual temperature and forecasted temperature of Algorithm-B with the window bases $w=6$ and $w=7$.

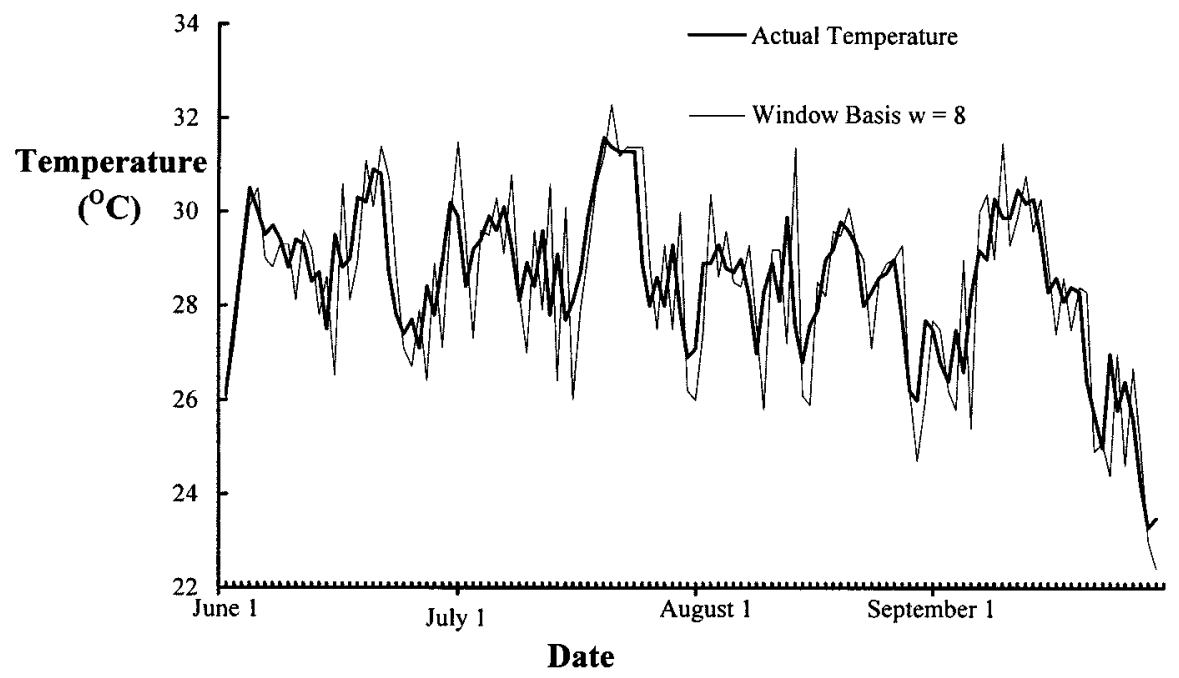

Fig. 8. Curve of the actual temperature and forecasted temperature of Algorithm-B with the window basis $w=8$. 
Based on (13), we can get the fuzzified forecasted variation $f($ June 15,1996$)$ shown as follows:

$$
f(\text { June } 15,1996)=\left[\begin{array}{lllllll}
0 & 0.5 & 0.5 & 0 & 0 & 0 & 0
\end{array}\right] \text {. }
$$

Step 8) Defuzzify the fuzzified forecasted variations of the main-factor fuzzy time series obtained in Step 7. We use the following combined method to defuzzify the fuzzified forecasted variations:

1) If the grades of membership of the fuzzified forecasted variation are all 0 , then we set the forecasted variation to 0 .

2) If the maximum membership of the fuzzified forecasted variation $f(t)$ occurred at $u_{i}$ and the midpoint of $u_{i}$ is $m_{i}$, then the forecasted variation is $m_{i}$. If the maximum membership of the fuzzified forecasted variation $f(t)$ occurred at $u_{1}, u_{2}, \ldots$, and $u_{k}$, and the midpoints of $u_{1}, u_{2}, \ldots$, and $u_{k}$ are $m_{1}, m_{2}, \ldots$, and $m_{k}$, respectively, then the forecasted variation is $\left(m_{1}+m_{2}+\cdots+m_{k}\right) / k$ [4].

For example, in the above, we can see that the maximum membership value of $f$ (June 15,1996$)$ is 0.5 which occurs at $u_{2}$ and $u_{3}$, where the midpoint of $u_{2}$ is -1.3 and the midpoint of $u_{3}$ is -0.7 . Thus, the forecasted variation of June 15,1996 is $=-1$.

Step 9) Calculate the forecasted data of the main-factor fuzzy time series. The forecasted data is equal to the forecasted variation plus the actual data of the last day of the main-factor fuzzy time series. For example, if the forecasted variation of June 15, 1996 , is -1 , and the actual daily average temperature of June 14, 1996 is 27.5 , then the forecasted average temperature of June 15, 1996 is equal to $27.5+(-1)=26.5$.

Figs. 1-4 show the forecasting results using Algorithm-A from June 1996 to September 1996, where Algorithm-A only uses one factor (i.e., the daily average temperature) for temperature prediction. Figs. 5-8 show the forecasting results using Algorithm-B from June 1996 to September 1996 with different window basis. Table IV shows the forecasting errors of the daily average temperature using Algorithm-A [7] and Algorithm-B with different window bases from June 1996 to September 1996 in Taipei. In general, the forecasting accuracy of the two-factors time-variant fuzzy time series algorithm Algorithm-B is better than the one-factor time-variant fuzzy time series algorithm Algorithm-A [7]. In order to further enhance the forecasting accuracy of the proposed algorithm Algorithm-B, we will modify Algorithm-B into Algorithm-B* to further reduce the forecasting errors.

In the following, we will propose the algorithm Algorithm-B* based on the concept of $\alpha$-significance level [27], where $\alpha \in$ $[0,1]$, and the repeated transition method, where Algorithm- $\mathrm{B}^{*}$ is essentially a modification of Algorithm-B.

Definition 3.4: Assume that $F(t)$ and $H(t)$ are fuzzy time series of the daily average temperature, where $H(t)$ is last year's $F(t), f(t)$ is the data of $F(t)$ at date $t$, and $h(t)$ is the data of $H(t)$ at date $t$. The boundary of $f(t)$ ranges from $h(t-k)$ to $h(t+k)$, where $k$ is the boundary length. Then, we can find the
TABLE IV

AvERAGE ForeCASTING ERRORS OF ALgORITHM-A AND ALGORITHM-B WiTH DIFFERENT WINDOW BASES FOR TEMPERATURE PREDICTION

\begin{tabular}{|c|c|c|c|c|c|c|}
\hline & \multicolumn{6}{|c|}{ Window Bases } \\
\hline & $w=2$ & $w=3$ & $w=4$ & $w=5$ & $w=6$ & $w=7 \quad w=8$ \\
\hline $\begin{array}{l}\text { Algorithm-A [7] to Forecast } \\
\text { the Temperature of June }\end{array}$ & $3.04 \%$ & $3.48 \%$ & $3.49 \%$ & $3.57 \%$ & $3.81 \%$ & $3.88 \% 4.09 \%$ \\
\hline $\begin{array}{l}\text { Algorithm-B to Forecast the } \\
\text { Temperature of June }\end{array}$ & $2.90 \%$ & $3.23 \%$ & $3.37 \%$ & $3.44 \%$ & $3.67 \%$ & $3.82 \% 3.97 \%$ \\
\hline $\begin{array}{l}\text { Algorithm-A [7] to Forecast } \\
\text { the Temperature of July }\end{array}$ & $3.09 \%$ & $3.97 \%$ & $4.22 \%$ & $4.34 \%$ & $4.47 \%$ & $4.35 \% 4.58 \%$ \\
\hline $\begin{array}{l}\text { Algorithm-B to Forecast the } \\
\text { Temperature of July }\end{array}$ & $2.88 \%$ & $3.86 \%$ & $4.18 \%$ & $4.26 \%$ & $4.43 \%$ & $4.35 \% 4.54 \%$ \\
\hline $\begin{array}{l}\text { Algorithm-A [7] to Forecast } \\
\text { the Temperature of August }\end{array}$ & $3.49 \%$ & $3.72 \%$ & $3.79 \%$ & $3.83 \%$ & $3.67 \%$ & $3.66 \% 3.72 \%$ \\
\hline $\begin{array}{l}\text { Algorithm-B to Forecast the } \\
\text { Temperature of August }\end{array}$ & $3.49 \%$ & $3.68 \%$ & $3.71 \%$ & $3.79 \%$ & $3.58 \%$ & $3.56 \% 3.63 \%$ \\
\hline $\begin{array}{l}\text { Algorithm-A [7] to Forecast } \\
\text { the Temperature of September }\end{array}$ & $3.37 \%$ & $3.67 \%$ & $3.72 \%$ & $3.56 \%$ & $3.78 \%$ & $3.68 \% 3.60 \%$ \\
\hline $\begin{array}{l}\text { Algorithm-B to Forecast the } \\
\text { Temperature of September }\end{array}$ & $3.33 \%$ & $3.58 \%$ & $3.63 \%$ & $3.47 \%$ & $3.68 \%$ & $3.57 \% \quad 3.49 \%$ \\
\hline
\end{tabular}

TABLE $\mathrm{V}$

DAILY AVERAGE TEMPERATURE FROM MAY 1995 TO OCTOBER 1995 IN TAIPEI (UNIT: $\left.{ }^{\circ} \mathrm{C}\right)[2]$

\begin{tabular}{|c|c|c|c|c|c|c|}
\hline Day & May & June & July & August & September & October \\
\hline 1 & 27.0 & 28.9 & 28.4 & 28.4 & 29.8 & 28.4 \\
\hline 2 & 26.5 & 28.8 & 29.1 & 26.7 & 29.8 & 28.8 \\
\hline 3 & 25.0 & 28.4 & 28.7 & 26.1 & 29.6 & 30.1 \\
\hline 4 & 20.7 & 28.2 & 28.6 & 28.8 & 30.3 & 29.8 \\
\hline 5 & 18.5 & 25.6 & 29.0 & 27.5 & 29.7 & 28.3 \\
\hline 6 & 22.3 & 26.0 & 29.5 & 28.4 & 30.0 & 25.2 \\
\hline 7 & 21.7 & 27.5 & 30.1 & 28.7 & 29.8 & 24.8 \\
\hline 8 & 23.5 & 27.7 & 30.1 & 29.8 & 30.5 & 24.6 \\
\hline 9 & 24.6 & 24.6 & 28.6 & 30.6 & 30.1 & 24.0 \\
\hline 10 & 24.6 & 25.0 & 27.2 & 30.8 & 29.7 & 24.1 \\
\hline 11 & 23.2 & 24.4 & 26.5 & 29.8 & 29.5 & 24.7 \\
\hline 12 & 25.6 & 26.1 & 26.4 & 28.6 & 27.3 & 24.8 \\
\hline 13 & 26.3 & 25.8 & 27.8 & 27.5 & 27.7 & 24.5 \\
\hline 14 & 25.8 & 26.5 & 28.5 & 27.9 & 27.2 & 26.4 \\
\hline 15 & 21.0 & 26.0 & 27.2 & 29.1 & 27.7 & 25.6 \\
\hline 16 & 18.3 & 27.4 & 29.4 & 29.4 & 26.2 & 24.2 \\
\hline 17 & 21.3 & 29.0 & 30.0 & 30.1 & 25.4 & 24.1 \\
\hline 18 & 22.9 & 27.8 & 31.1 & 30.0 & 25.4 & 24.5 \\
\hline 19 & 25.9 & 29.9 & 31.3 & 30.3 & 25.8 & 23.9 \\
\hline 20 & 27.6 & 30.0 & 31.1 & 30.7 & 23.2 & 24.8 \\
\hline 21 & 22.7 & 30.4 & 32.1 & 30.8 & 21.6 & 23.9 \\
\hline 22 & 19.2 & 31.5 & 32.2 & 29.7 & 22.9 & 23.6 \\
\hline 23 & 20.5 & 31.2 & 28.8 & 28.9 & 23.4 & 24.2 \\
\hline 24 & 24.2 & 30.7 & 26.8 & 26.6 & 25.1 & 23.8 \\
\hline 25 & 27.0 & 30.8 & 27.0 & 25.9 & 25.4 & 21.4 \\
\hline 26 & 27.8 & 31.2 & 29.0 & 28.1 & 25.9 & 22.2 \\
\hline 27 & 27.7 & 31.5 & 29.0 & 29.4 & 26.6 & 23.0 \\
\hline 28 & 27.9 & 25.7 & 29.9 & 30.6 & 27.1 & 23.5 \\
\hline 29 & 28.7 & 28.0 & 29.9 & 30.9 & 26.3 & 23.3 \\
\hline 30 & 29.3 & 28.0 & 28.6 & 29.4 & 27.6 & 24.0 \\
\hline 31 & 29.3 & & 27.7 & 30.5 & & 22.8 \\
\hline
\end{tabular}

maximum $T_{\max }$ and the minimum $T_{\min }$ of these $2 k+1$ data. The forecasted temperature of date $t$ can not be bigger than $T_{\max }$ and not be smaller than $T_{\min }$. The algorithm Algorithm-B* is now presented as follows:

\section{Algorithm-B*:}

Step 1) Partition the historical data into suitable groups.

Step 2) Compute the variations of the main-factor fuzzy time series between any two continuous data. Find the maximum decrease $D_{L}$ and the maximum increase $D_{R}$, and define the universe of discourse $U=\left[D_{L}-D_{1}, D_{R}+D_{2}\right]$, where $D_{1}$ and $D_{2}$ are suitable positive numbers. 


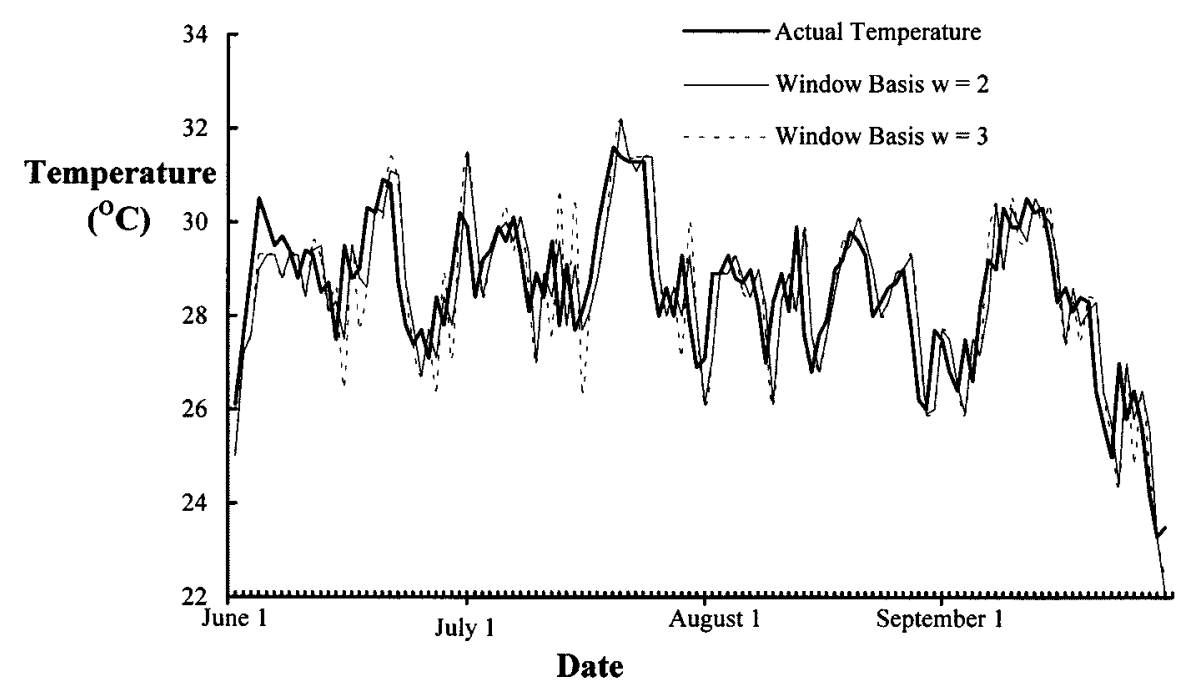

Fig. 9. Curve of the actual temperature and forecasted temperature of Algorithm- $\mathrm{B}^{*}$ with the window bases $w=2$ and $w=3$.

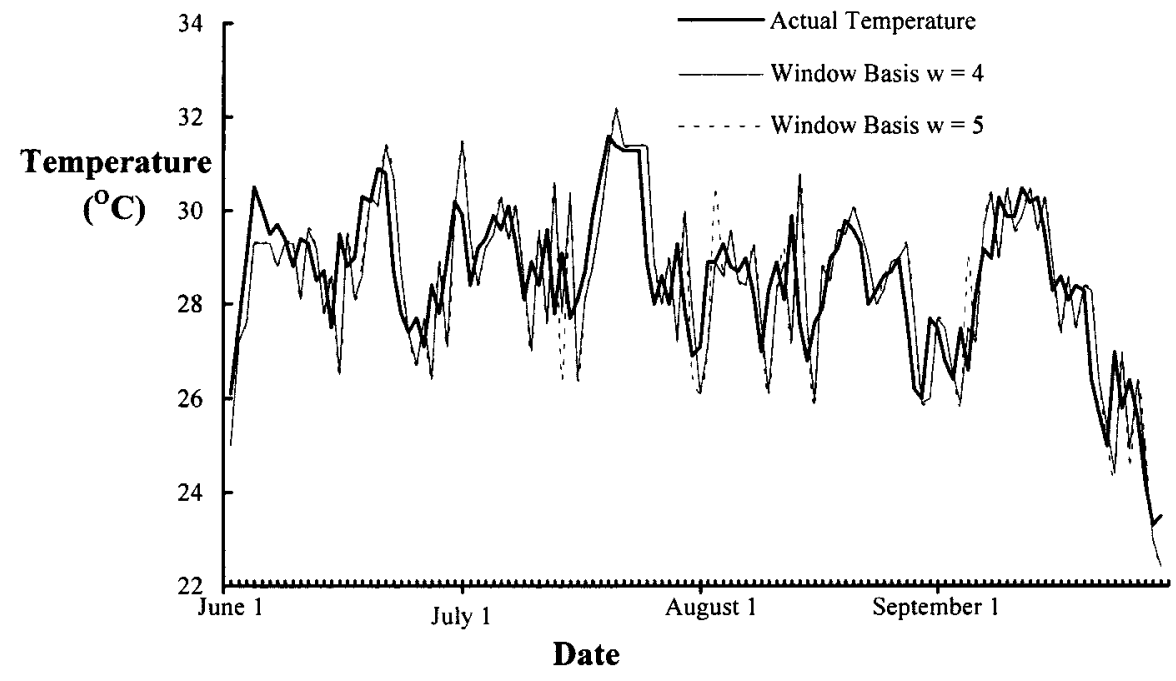

Fig. 10. Curve of the actual temperature and forecasted temperature of Algorithm- $\mathrm{B}^{*}$ with the window bases $w=4$ and $w=5$.

Step 3) Partition the universe of discourse $U$ into several even length intervals.

Step 4) Define fuzzy sets on the universe of discourse $U$ for the main-factor fuzzy time series $F(t)$.

Step 5) Define fuzzy sets on the universe of discourse $U$ for the second-factor fuzzy time series $G(t)$.

Step 6) Fuzzify the variation of the historical data of the main-factor fuzzy time series and fuzzify the historical data of the second-factor fuzzy time series.

Step 7) Choose a suitable window basis $w$. Define the criterion vector $C(t)$, the operation matrix $O^{w}(t)$, and the second-factor vector $S(t)$. Then, calculate the fuzzy relationship matrix $R(t)$ between the criterion vector $C(t)$, the operation matrix $O^{w}(t)$, and the second-factor vector. The fuzzified forecasted variation of the main-factor fuzzy time series can be obtained from the fuzzy relationship matrix.
Step 8) Defuzzify the fuzzified forecasted variations of the main-factor obtained in Step 7.

1) Compute the $\alpha$-significance level [27] $(f(t))_{\alpha}$ of the fuzzified forecasted variation $f(t)$ as follows:

$$
\begin{aligned}
f(t) & =\left[\begin{array}{llll}
f_{1} & f_{2} & \cdots & f_{m}
\end{array}\right] \\
(f(t))_{\alpha} & =\left[\begin{array}{llll}
f_{1 \alpha} & f_{2 \alpha} & \cdots & f_{m \alpha}
\end{array}\right]
\end{aligned}
$$

where $f(t)$ is the fuzzified forecasted variation of date $t$ represented by a fuzzy set in the fuzzy time series $F(t), m$ is the number of elements in the universe of discourse, and $\alpha \in[0,1]$. If $f_{i} \geq \alpha$, then let $f_{i \alpha}=f_{i}$; if $f_{i}<\alpha$, then let $f_{i \alpha}=0$, where $1 \leq i \leq m$. 


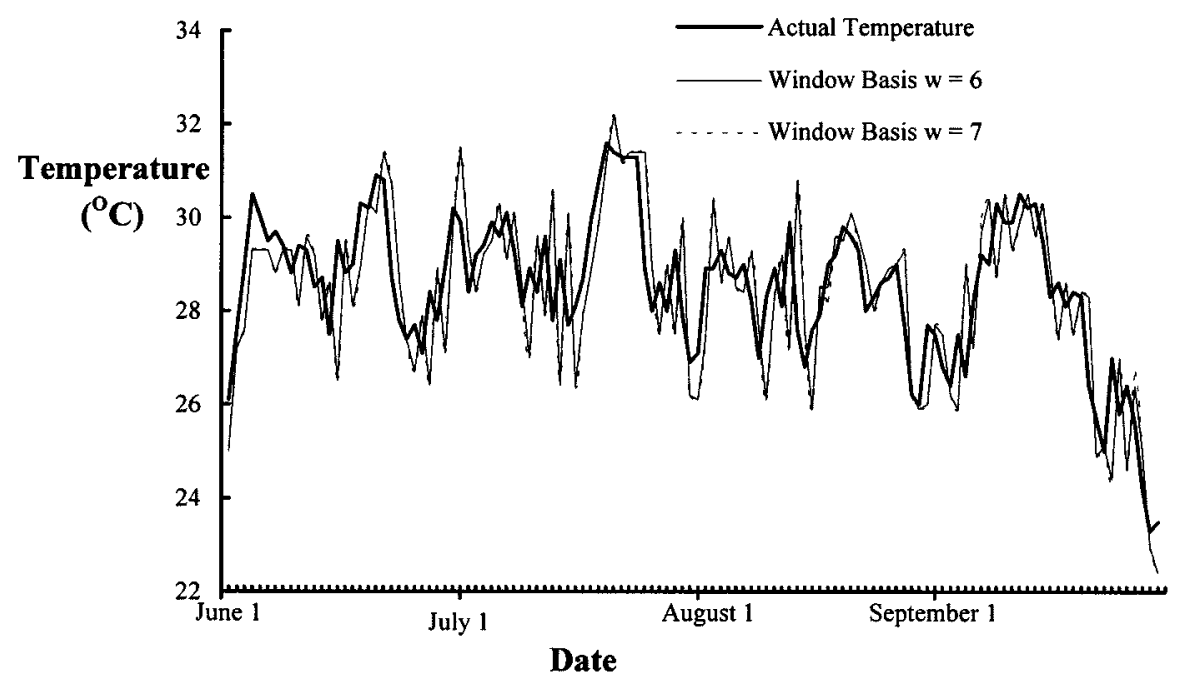

Fig. 11. Curve of the actual temperature and forecasted temperature of Algorithm- $\mathrm{B}^{*}$ with the window bases $w=6$ and $w=7$.

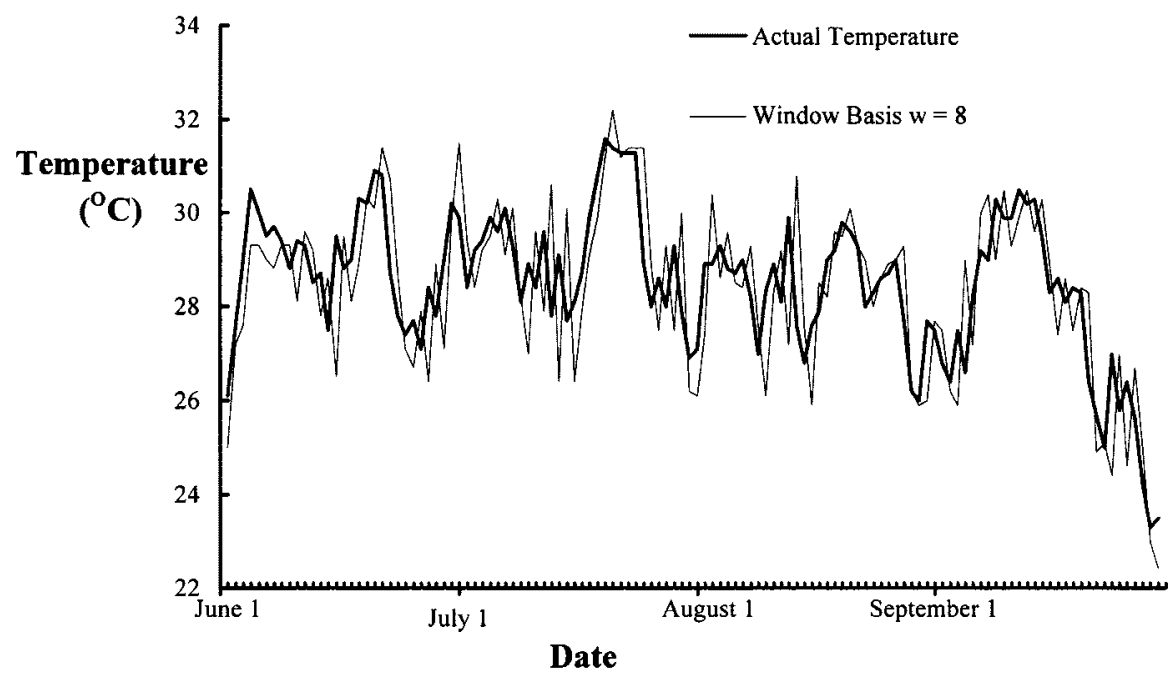

Fig. 12. Curve of the actual temperature and forecasted temperature of Algorithm- $\mathrm{B}^{*}$ with the window basis $w=8$.

In this paper, we set the value of the significance level $\alpha=0.5$.

2) If the grades of membership of the $\alpha$-significance level forecasted variation $(f(t))_{\alpha}$ are all 0 , then we set the forecasted variation to 0 .

3 ) If the grades of membership of the $\alpha$-significance level forecasted variation $(f(t))_{\alpha}$ have only one maximum $u_{i}$, and the midpoint of $u_{i}$ is $m_{i}$, then the forecasted variation of date $t$ is $m_{i}$. If the grades of membership of the $\alpha$-significance level forecasted variation $(f(t))_{\alpha}$ have more than one maximum $u_{1}, u_{2}, \ldots$, and $u_{k}$, and the midpoints of $u_{1}, u_{2}, \ldots$, and $u_{k}$ are $m_{1}, m_{2}, \ldots$, and $m_{k}$, respectively, then the forecasted variation of date $t$ is $\left(m_{1}+m_{2}+\cdots+m_{k}\right) / k$.

Step 9) Calculate the forecasted data of the main-factor fuzzy time series. The forecasted data is equal to the forecasted variation plus the actual data of the last day of the main-factor fuzzy time series.
Step 10) Set the boundary length to $k$. Then, we can find the maximum $T_{\max }$ and the minimum $T_{\min }$ among the data from the date $t-k$ of last year to the date $t+k$ of last year. The forecasted temperature of date $\mathrm{t}$ obtained in Step 9 can not be bigger than $T_{\max }$ and not be smaller than $T_{\min }$. If the forecasted temperature is larger than $T_{\max }$, then we set the forecasted temperature to $T_{\max }$; if the forecasted temperature is smaller than $T_{\min }$, then we set the forecasted temperature to $T_{\min }$. For example, assume that we set the window basis $w=4$ and the boundary length $k=10$, and we want to forecast the temperature of June 6, 1996, in Taipei. Furthermore, assume that the forecasted temperature of June 6, 1996, by using the above steps is $30.0^{\circ} \mathrm{C}$. Table $\mathrm{V}$ shows the daily average temperature from May 1995 to October 1995 in Taipei. The boundary data is from May 27, 1995 to June 16, 1995. According to Table V, we can find that $T_{\max }=29.3^{\circ} \mathrm{C}$ and $T_{\min }=24.4^{\circ} \mathrm{C}$. Because 30 
TABLE VI

Comparison of the Average Forecasting Errors of Algorithm-A, Algorithm-B and Algorithm-B* to Forecast the Temperature From June 1996 TO SEPTEMBER 1996 IN TAIPEI WITH DIFFERENT WINDOW BASES

\begin{tabular}{|c|c|c|c|c|c|c|c|}
\hline & \multicolumn{3}{|c|}{ Window } & \multicolumn{2}{|l|}{ Bases } & \multirow[b]{2}{*}{$w=7$} & \multirow[b]{2}{*}{$w=8$} \\
\hline & $w=2$ & $w=3$ & $w=4$ & $w=5$ & $w=6$ & & \\
\hline $\begin{array}{l}\text { Algorithm-A [7] to Forecast } \\
\text { the Temperature of June }\end{array}$ & $3.04 \%$ & $3.48 \%$ & $3.49 \%$ & $3.57 \%$ & $3.81 \%$ & $3.88 \%$ & $4.09 \%$ \\
\hline $\begin{array}{l}\text { Algorithm-B to Forecast the } \\
\text { Temperature of June }\end{array}$ & $2.90 \%$ & $3.23 \%$ & $3.37 \%$ & $3.44 \%$ & $3.67 \%$ & $3.82 \%$ & $3.97 \%$ \\
\hline $\begin{array}{l}\text { Algorithm-B* to Forecast the } \\
\text { Temperature of June }\end{array}$ & $2.88 \%$ & $3.16 \%$ & $3.24 \%$ & $3.33 \%$ & $3.39 \%$ & $3.53 \%$ & $3.67 \%$ \\
\hline $\begin{array}{l}\text { Algorithm-A [7] to Forecast } \\
\text { the Temperature of July }\end{array}$ & $3.09 \%$ & $3.97 \%$ & $4.22 \%$ & $4.34 \%$ & $4.47 \%$ & $4.35 \%$ & $4.58 \%$ \\
\hline $\begin{array}{l}\text { Algorithm-B to Forecast the } \\
\text { Temperature of July }\end{array}$ & $2.88 \%$ & $3.86 \%$ & $4.18 \%$ & $4.26 \%$ & $4.43 \%$ & $4.35 \%$ & $4.54 \%$ \\
\hline $\begin{array}{l}\text { Algorithm-B* to Forecast the } \\
\text { Temperature of July }\end{array}$ & $3.04 \%$ & $3.76 \%$ & $4.08 \%$ & $4.17 \%$ & $4.35 \%$ & $4.38 \%$ & $4.56 \%$ \\
\hline $\begin{array}{l}\text { Algorithm-A [7] to Forecast } \\
\text { the Temperature of August }\end{array}$ & $3.49 \%$ & $3.72 \%$ & $3.79 \%$ & $3.83 \%$ & $3.67 \%$ & $3.66 \%$ & $3.72 \%$ \\
\hline $\begin{array}{l}\text { Algorithm-B to Forecast the } \\
\text { Temperature of August }\end{array}$ & $3.49 \%$ & $3.68 \%$ & $3.71 \%$ & $3.79 \%$ & $3.58 \%$ & $3.56 \%$ & $3.63 \%$ \\
\hline $\begin{array}{l}\text { Algorithm- } \mathrm{B}^{*} \text { to Forecast the } \\
\text { Temperature of August }\end{array}$ & $2.75 \%$ & $2.77 \%$ & $3.30 \%$ & $3.40 \%$ & $3.18 \%$ & $3.15 \%$ & $3.19 \%$ \\
\hline $\begin{array}{l}\text { Algorithm-A [7] to Forecast } \\
\text { the Temperature of September }\end{array}$ & $3.37 \%$ & $3.67 \%$ & $3.72 \%$ & $3.56 \%$ & $3.78 \%$ & $3.68 \%$ & $3.60 \%$ \\
\hline $\begin{array}{l}\text { Algorithm-B to Forecast the } \\
\text { Temperature of September }\end{array}$ & $3.33 \%$ & $3.58 \%$ & $3.63 \%$ & $3.47 \%$ & $3.68 \%$ & $3.57 \%$ & $3.49 \%$ \\
\hline $\begin{array}{l}\text { Algorithm-B* to Forecast the } \\
\text { Temperature of September }\end{array}$ & $3.29 \%$ & $3.10 \%$ & $3.19 \%$ & $3.22 \%$ & $3.39 \%$ & $3.38 \%$ & $3.29 \%$ \\
\hline
\end{tabular}

${ }^{\circ} \mathrm{C}>T_{\max }$, we set the forecasted temperature of June 6,1996 , to $29.3{ }^{\circ} \mathrm{C}$.

Figs. 9-12 show the forecasting results from June 1996 to September 1996 by using Algorithm-B* with different window bases. Table VI shows a comparison of the average forecasting errors of Algorithm-A, Algorithm-B, and Algorithm-B* with different window bases. We can see that the forecasting results of Algorithm-B* are better than the forecasting results of Algorithm-A and Algorithm-B. From Table VI, we can see that when window basis $w=2$, we almost can get the best forecasting results, and the forecasting results of a smaller window basis are better than the ones of a bigger window basis. This is because the forecasted temperature usually is related to the temperature of the recent days. Because the time complexities of the algorithms (i.e., Algorithm-B and Algorithm-B*) are dominated by Step 7, i.e., calculating the fuzzy relationship matrix $R(t)$, where $R(t)=O^{w}(t) \otimes S(t) \otimes C(t)$ as shown in (12) and the time complexity for calculating $R(t)$ is $O(w m)$, where $w$ is the window basis and $m$ is the number of elements in the universe of discourse $U$ derived in Step 3 of the proposed algorithms and because there are $c$ groups of the historical data derived in Step 1 of the proposed algorithms, the time complexities of the proposed algorithms are $O(\mathrm{cwm})$, respectively.

\section{CONCLUSIONS}

In this paper, we have proposed a new fuzzy time series model called the two-factors time-variant fuzzy time series model for handling forecasting problems. Based on the pro- posed model, we develop two algorithms (i.e., Algorithm-B and Algorithm-B*) for temperature prediction. From Table VI, we can see that the forecasting results of Algorithm-B* are better than the forecasting results of Algorithm-A and Algorithm-B. Both of these algorithms have the advantages that they can get good forecasting results. The time complexities of the proposed algorithms are $O(\mathrm{cwm})$, respectively, where $c$ is the number of partitioned groups in the historical data, $w$ is the window basis, and $m$ is the number of elements in the universe of discourse.

\section{ACKNOWLEDGMENT}

The authors would like to thank the referees for providing very helpful comments and suggestions; their insight and comments led to a better presentation of the ideas expressed in this paper.

\section{REFERENCES}

[1] H. Bentley, "Time series analysis with REVEAL," Fuzzy Sets Syst., vol. 23, no. 1, pp. 97-118, 1987.

[2] Central Weather Bureau, The Historical Data of the Daily Average Temperature and the Daily Cloud Density Taipei, Taiwan, R.O.C, 1996. (from January 1995 to September 1996).

[3] S. M. Chen, "A new method for forecasting enrollments using fuzzy time series," in Proc. 1995 National Computer Symp. Chungli, Taoyuan, Taiwan, R.O.C., 1995, pp. 603-609.

[4] - "Forecasting enrollments based on fuzzy time series," Fuzzy Sets Syst., vol. 81, no. 3, pp. 311-319, 1996.

[5] M. Y. Day, "Research of Applying Genetic Algorithms to Fuzzy Forecasting-Focus on Sales Forecasting," M.S. thesis, Tamkang Univ., Taipei, Taiwan, R.O.C., 1995. 
[6] J. R. Hwang, S. M. Chen, and C. H. Lee, "A new method for handling forecasting problems based on fuzzy time series," in Proc. 7th Int. Conf. Information Management. Chungli, Taoyuan, Taiwan, R.O.C., 1996, pp. 312-321.

[7] — , "Handling forecasting problems using fuzzy time series," Fuzzy Sets Syst., vol. 100, no. 2, pp. 217-228, 1998.

[8] A. Kandel, Fuzzy Mathematical Techniques with Applications. Reading, MA: Addison-Wesley, 1996.

[9] A. Kaufmann and M. M. Gupta, Fuzzy Mathematical Models in Engineering and Management Science. Amsterdam, The Netherlands: North-Holland, 1988.

[10] G. J. Klir and T. A. Folger, Fuzzy Sets, Uncertainty, and Information. Englewood Cliffs, NJ: Prentice-Hall, 1988.

[11] G. J. Klir and B. Yuan, Fuzzy Sets and Fuzzy Logic: Theory and Applications. Englewood Cliffs, NJ: Prentice-Hall, 1995.

[12] K. S. Leung and W. Lam, "Fuzzy concepts in expert systems," IEEE Comput., vol. 21, no. 9, pp. 43-56, 1988.

[13] _ - "A fuzzy expert system shell using both exact and inexact reasoning," J. Autom. Reasoning, vol. 5, no. 2, pp. 207-233, 1989.

[14] S. Mabuchi, "A proposal for a defuzzification strategy by the concept of sensitivity analysis," Fuzzy Sets Syst., vol. 55, no. 1, pp. 1-14, 1993.

[15] T. A. Runkler and M. Glesner, "A set of axioms for defuzzification strategies towards a theory of rational defuzzification operator," in Proc. 2nd IEEE Int. Conf. Fuzzy Systems, San Francisco, CA, 1993, pp. 1161-1166.

[16] Q. Song and G. Bortolan, "Some properties of defuzzification neural networks," Fuzzy Sets Syst., vol. 61, no. 1, pp. 83-89, 1994.

[17] Q. Song and B. S. Chissom, "Fuzzy time series and its models," Fuzzy Sets Syst., vol. 54, no. 3, pp. 269-277, 1993.

[18] — , "Forecasting enrollments with fuzzy time series—Part I," Fuzzy Sets Syst., vol. 54, no. 1, pp. 1-9, 1993.

[19] — , "Forecasting enrollments with fuzzy time series—Part II," Fuzzy Sets Syst., vol. 62, no. 1, pp. 1-8, 1994.

[20] Q. Song and R. P. Leland, "Adaptive learning defuzzification techniques and applications," Fuzzy Sets Syst., vol. 81, no. 3, pp. 321-329, 1996.

[21] J. Sullivan and W. H. Woodall, "A comparison of fuzzy forecasting and Markov modeling," Fuzzy Sets Syst., vol. 64, no. 3, pp. 279-293, 1994.

[22] L. X. Wang, A Course in Fuzzy Systems and Control. Englewood Cliffs, NJ: Prentice-Hall, 1997.

[23] W. Wu, "Fuzzy reasoning and fuzzy relational equations," Fuzzy Sets Syst., vol. 20, no. 1, pp. 67-78, 1986.

[24] R. R. Yager, "Implementing fuzzy logic controllers using a neural network," Fuzzy Sets Syst., vol. 48, no. 1, pp. 53-64, 1992.

[25] R. R. Yager and D. Filev, "On the issue of defuzzification and selection based on a fuzzy set," Fuzzy Sets Syst., vol. 55, no. 3, pp. 255-271, 1993.

[26] —-, "SLIDE: A simple adaptive defuzzification method," IEEE Trans. Fuzzy Systems, vol. 1, no. 1, pp. 69-78, 1993.

[27] Y. Yuan and M. J. Shaw, "Induction of fuzzy decision trees," Fuzzy Sets Syst., vol. 69, no. 2, pp. 125-139, 1995

[28] L. A. Zadeh, "Fuzzy sets," Inform. Contr., vol. 8, pp. 338-353, 1965.

[29] _ - "Outline of a new approach to the analysis of complex system and decision processes," IEEE Trans. Syst., Man, Cybern., vol. SMC-3, pp. 28-44, 1973.
[30] _ - "The concept of a linguistic variable and its application to approximate reasoning, part I-III," Inform. Sci., vol. 8, 9, pp. 199-249, 301-357, 43-80, 1975 .

[31] Z. Li, Z. Chen, and J. Li, "A model of weather forecast by fuzzy grade statistics,” Fuzzy Sets Syst., vol. 26, no. 3, pp. 275-281, 1988.

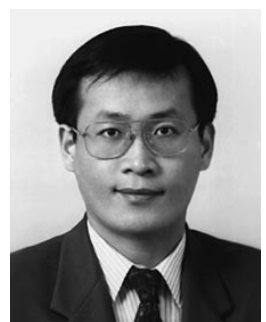

Shyi-Ming Chen (M'88-SM'96) was born on January 16, 1960, in Taipei, Taiwan, R.O.C. He received the B.S. degree in electronic engineering from National Taiwan University of Science and Technoilogy, Taipei, in 1992, and the M.S. and Ph.D. degrees in electrical engineering, all from National Taiwan University, Taipei, in 1982, 1986, and 1991, respectively.

From August 1987 to July 1989 and from August 1990 to July 1991, he was with the Department of Electronic Engineering, Fu-Jen University, Taipei. From August 1991 to July 1996, he was an Associate Professor in the Department of Computer and Information Science, National Chiao Tung University, Hsinchu, Taiwan. From August 1996 to July 1998 he was a Professor in the Department of Computer and Information Science of the same university. Since August 1998, he has been a Professor in the Department of Electronic Engineering, National Taiwan University of Science and Technology. His current research interests include fuzzy systems, database systems, expert systems, and artificial intelligence. He has published more than 100 papers in referred journals and conference proceedings.

Dr. Chen was the winner of the 1994 Outstanding Paper Award of the Journal of Information and Education and the winner of the 1995 Outstanding Paper Award of the Computer Society of the R.O.C. He was also the winner of the 1997 Outstanding Youth Electrical Engineer Award of the Chinese Institute of Electrical Engineering, R.O.C, and the Outstanding Paper Award of the 1999 National Computer Symposium, R.O.C. He is a member of the ACM, the International Fuzzy Systems Association (IFSA), and the Phi Tau Phi Scholastic Honor Society. He is an executive committee member of the Chinese Fuzzy Systems Association (CFSA). He is an executive committee member of the Taiwanese Association for Artificial Intelligence (TAAI). He is an editor of the Journal of the Chinese Grey System Association. He is listed in International Who's Who of Professionals, Marquis Who's Who in the World, and Marquis Who's Who in Science and Engineering.

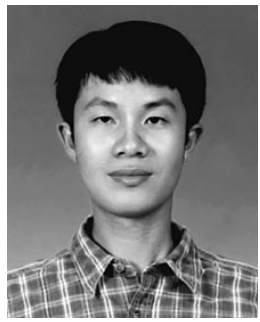

Jeng-Ren Hwang was born on May 4, 1973, in Tainan, Taiwan, R.O.C.. He received the B.S. degree in computer science from National Tsing Hua University, Hsinchu, Taiwan, in June 1995 and the M.S. degree in the Department of Computer and Information Science at National Chiao Tung University, Hsinchu, in June 1997. His current research interests include fuzzy systems, database systems, and artificial intelligence. 